\title{
Les femmes, la culture et les arts en Europe entre Moyen Âge et Renaissance, sous la direction de Cynthia J. BROWN et Anne-Marie LEGARÉ
}

\section{Paola Cifarelli}

\section{OpenEdition}

\section{Journals}

\section{Édition électronique}

URL : http://journals.openedition.org/studifrancesi/16239

DOI : 10.4000/studifrancesi. 16239

ISSN : 2427-5856

Éditeur

Rosenberg \& Sellier

\section{Édition imprimée}

Date de publication : 1 juillet 2019

Pagination : 141-142

ISSN : 0039-2944

\section{Référence électronique}

Paola Cifarelli, «Les femmes, la culture et les arts en Europe entre Moyen Âge et Renaissance, sous la direction de Cynthia J. Brown et Anne-Marie Legaré », Studi Francesi [En ligne], 187 (LXIII | I) | 2019, mis en ligne le 01 juin 2019, consulté le 25 janvier 2021. URL : http://journals.openedition.org/ studifrancesi/16239; DOI : https://doi.org/10.4000/studifrancesi.16239

Ce document a été généré automatiquement le 25 janvier 2021.

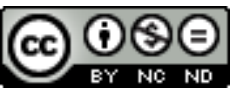

Studi Francesi è distribuita con Licenza Creative Commons Attribuzione - Non commerciale - Non opere derivate 4.0 Internazionale. 
Les femmes, la culture et les arts en Europe entre Moyen Âge et Renaissance, sous la direction de Cynthia J. BROWN et Anne-Marie LEGARÉ

\author{
Paola Cifarelli
}

\title{
RÉFÉRENCE
}

Les femmes, la culture et les arts en Europe entre Moyen Âge et Renaissance, sous la direction de Cynthia J. BRown et Anne-Marie LEGARÉ, Turnhout, Brepols, 2016, VIII + 560 pp.

1 Bien qu'avec un peu de retard, nous tenons à signaler ce beau volume consacré au mécénat artistique, bibliophilique et littéraire des femmes entre Moyen Âge tardif et première Renaissance. Comme A.-M. LEGARÉ le rappelle dans l'Introduction (pp. 1-9), les questions liées à l'adaptation des textes, des cycles iconographiques et des messages que l'on inscrit dans ceux-ci méritent d'être approfondies et le croisement entre disciplines complémentaires, ainsi que le débordement des frontières nationales, ne peuvent que contribuer à enrichir la réflexion.

2 Les vingt-deux contributions sont réparties en cinq sections, intitulées respectivement «Mécénat artistique et bibliophilique» (I), «Femmes éduquées, femmes éducatrices» (II), «Une iconographie féminisante» (III), «Herö̈nes vertueuses» (IV), «L'image "politique" au féminin» (V). Nous rendrons compte ici des articles concernant la culture francophone.

3 La personnalité de Marie de Clèves, troisième femme de Charles d'Orléans, est au cœur de l'étude de Paola CORTI (Mécénat et culture dévote chez Marie de Clèves, duchesse d'Orléans (1426-1487), pp. 13-32), consacrée spécifiquement à la culture dévote de la duchesse et aux manuscrits à caractère religieux, moral ou d'édification ayant fait partie de sa bibliothèque personnelle, dont le magnifique codex Paris, BnF, fr.966, connu 
généralement comme Livre de prières; un tableau réunit aussi les indications relatives aux trente-quatre manuscrits lui ayant appartenu. Tout aussi intéressante est la bibliothèque personnelle de Marguerite de Rohan, femme de Jean d'Angoulême, examinée par Valérie GUÉANT (Marguerite de Rohan à la cour d'Angoulême: culture littéraire et art du livre, pp. 33-54): six manuscrits sont attribués à la bibliothèque de la comtesse, particulièrement significatifs pour montrer la communauté d'intérêts intellectuels avec son mari (fr. 1476, Livre de Messire Guy de Warewick), les dynamiques culturelles à la cour de Cognac (fr. 2230, Livre de paix et d'amitié, et n.a.l. 727, contenant entre autres un recueil de onze rondeaux), son influence politique (poème liminaire dans le ms. fr. 1673, Enseignements à Madame d'Angoulême) et les caractéristiques de sa posture dévotionnelle (fr. 684, Miroir du monde, et Garrett 55, Livre d'Heures, dont le cycle iconographique par le Maître des Missels Della Rovere est particulièrement original). À peu près dans les mêmes années, Jeanne de France femme de Jean II de Bourbon posséda une petite collection de quatorze mss que Samuel GRAS (Les manuscrits enluminés pour Jeanne de France, duchesse de Bourbon, pp. 55-71) examine du point de vue artistique, en s'arrêtant particulièrement sur quatre mss enluminés qui furent offerts à la duchesse, dont l'exemplaire Paris, BnF, fr. 329 de La Bouquechardière, le ms fr. 989 contenant la Défense de la conception immaculée de la Vierge Marie, et le ms fr. 1866 renfermant La Gésine morale; parmi les codex commandités par Jeanne de France, les mss fr. 227 (traduction du De Casibus de Boccace par Laurent de Premierfait) et fr. 1847 (Livre de la mendicité spirituelle de Jean Gerson) sont attribués ici respectivement aux enlumineurs connus sous le nom de Maître de Jeanne de France et Maître du cardinal de Bourbon. Des problèmes d'attribution d'ordre différent se posent pour deux Livres d'Heures (n.a.l. 3244 et La Haye, KB, 74 G 22). Mathieu DeLDiQUE se penche par contre sur les manuscrits appartenus à Anne de Graville et à sa mère, jusque là inconnue en tant que commanditaire (Bibliophiles de mère en fille: Marie de Balsac ( $\dagger 1504)$ et Anne de Graville († 1540), pp. 73-88); six mss lui sont restitués sur la base des armoiries peintes. Lieve DE KESEL reconstitue, quant à lui, l'œuvre du Maître des Livres de Prières auquel Marguerite d'Autriche et d'autres femmes mécènes s'adressèrent pour leurs commandes de manuscrits (New Perspectives on Devotional Manuscripts Associated with Margaret of Austria and Her Relations: The Role of the Prayer Books Master, pp. 89-113).

Si avec les contributions de Kathy KRAUSE ('Via femina': Female Patronage of Vernacular Religious Texts in Thirteenth-Century Picardie, pp.117-134) et Anne JENNY-CLARK (Les bréviaires, objets de transmission entre chanoinesses à la collégiale Sainte-Waudru de Mons, Hainaut, pp. 151-174) permettent d'évaluer l'érudition de certains milieux culturels animés par les femmes et l'attention extrême que celles-ci portent à la valeur des livres manuscrits, l'étude des mss fr. 244 et 245 conservant la traduction de la Legenda aurea par Jean de Vignay fait ressortir l'influence de la destinataire sur le programme iconographique (S.C. KAPLAN, La "Légende dorée", Paris, BnF fr. 244-245 (1480-1485), pp. 197-220); dominé par la présence féminine, le cycle d'illustrations aurait été conçu pour "plaire à Catherine de Coëtivy» (p. 199).

5 Anneliese POLLOCK RENCK (Traduction et adaptation d'un manuscrit des "XXI Epistres d'Ovide" appartenant à Louise de Savoie, pp. 221-239) analyse la traduction des Héroïdes d'Ovide par Octovien de Saint-Gelais en montrant que la traduction minimise l'importance du corps féminin en modifiant la source au niveau des descriptions et des métaphores, tandis que les illustrations dans le ms fr. 875, conçu pour Louise de Savoie et enluminé par Robinet Testard, mettent beaucoup plus en avant les femmes par rapport au 
programme iconographique correspondant dans le ms Oxford, Balliol College 383, créé pour un homme. C'est par contre le lectorat féminin qui est en cause dans l'article de Renée-Claude BREITENSTEIN (Tensions fécondes dans la construction de publics féminins à l'aube de la Renaissance française, pp. 241-257): deux procédés opposés mais comparables quant à la stratégie qui les sous-tend sont à l'œuvre dans la Nef des femmes vertueuses (1502), où Symphorien Champier multiplie les stratégies pour superposer plusieurs publics différents à partir de la dédicace à Anne de Bretagne, et dans la Louenge de mariage et recueil des hystoires des bonnes, vertueuses et illustres femmes de Pierre de Lesnauderie (1520); ici, l'auteur s'oriente vers un public féminin tout en ayant dédié son ouvrage à un homme. Ilaria ANDREOLI (Livres italiens et illustration des femmes à Lyon au xvie

sièclexvi ${ }^{\mathrm{e}}$

6 Le personnage de Marie de Bourgogne et son inscription dans le petit poème intitulé Le miroir des dames par Philippe Bouton (vers 1480, mss Bruxelles, KBR 10557 et Dijon, BM 3436) fait l'objet de la contribution d'Olga KARASKOVA (Une princesse dans le miroir: Marie de Bourgogne est-elle la dédicataire du "Miroir des dames" de Philippe Bouton?, pp. 291-308); le texte contient le portrait d'héroïnes et femmes vertueuses et plusieurs indices dans la miniature de dédicace du manuscrit bruxellois et dans le texte, particulièrement dans le choix des personnages féminins, permettent d'affirmer que l'ouvrage fut dédié à la duchesse.

7 Catherine GaUllieR-BOUgassas (Perrinet du Pin et le mécénat de la duchesse de Savoie Anne de Lusignan: le "Roman de Philippe de Madien" et les rêves orientaux d'une princesse chypriote, pp. 345-355) examine le roman-fleuve ayant pour protagoniste l'ancêtre d'Alexandre le Grand nommé Philippe de Madien composé par l'historien de la maison de Savoie Perrinet du Pin (1447); conservé par quatre manuscrits et deux imprimés, il fut dédié à la duchesse Anne de Lusignan, et le personnage féminin du roman, ainsi que les aventures visant la reconquête de l'empire byzantin, seraient modelés sur les préoccupations politiques de la dédicataire.

Pierre de Vaux est l'auteur, en 1447, d'une vie de sainte Colette, réformatrice de l'ordre des Clarisses (ms Gand, Monasterium 'Bethlehem' des Zusters Clarissen-Coletienen, n. 8); conçu pour la canonisation de Colette de Corbie, le codex qui nous a transmis le texte fut offert par Marie d'York aux Clarisses de Gand; le modèle hagiographique de saint François y est féminisé avec une mise en relief des thèmes de la fécondité, de la chasteté et de la virginité, tandis que la duchesse d'York est associée à la sainte (Andrea PEARSON, Margaret of York, Colette of Corbie, and the Possibilities of Female Agency, pp. 357-365). Cynthia J. BROWN (Parenté royale et livresque: une anthologie manuscrite dans la bibliothèque de Charlotte de Savoie, pp.367-386) fournit l'édition du poème intitulé Congratulations et graces de la nativité de Charles, ainsné fils du roy Loys unziesme de ce nom ( $m$ s fr. 2222, ff. 1-8). Le croisement entre naissance du dauphin et nativité du Christ d'une part, mère terrestre et mère divine de l'autre se réverbère dans la miniature ornant le manuscrit, tandis que la relation complexe entre écrivain et femme mécène vise à promouvoir le rôle politique et intellectuel de Charlotte de Savoie, dédicataire du texte, en l'exaltant comme modèle à imiter.

9 Tracy ADAMS (Theorizing Female Regency: Anne of France's "Enseignements à sa fille", pp. 357-401) s'interroge sur l'éducation des femmes de la très haute noblesse en vue de la possibilité qu'elles assument la régence du royaume, à partir de l'exemple d'Anne de France, femme de Pierre de Beaujeu. Dans le ms aujourd'hui perdu qui nous a conservé 
l'ouvrage, destiné à sa fille Suzanne de Bourbon, le texte dialogue avec l'Histoire du siège de Brest d'Antoine de la Sale, qui partage avec lui l'emphase sur la vertu de Prudence. Enfin, Aria DAL MOLIN (Renée de France, spectatrice privilégiée de "La Lena" de Ludovic Arioste, pp. 403-414) formule l'hypothèse que la pièce d'Arioste, connue dans deux versions successives, aurait été adaptée pour mettre en relief la dimension politique du mariage entre Renée de France et Hercule II d'Este à travers un nouveau prologue excentrique par rapport aux conventions des prologues dramatiques italiens, qui ouvrirait la comédie à un public féminin.

10 La dernière section de ce volume est constituée par la bibliographie, très riche et particulièrement utile pour les chercheurs à cause de son caractère thématique, ainsi que par une série d'index consacrés aux manuscrits et éditions cités, aux noms des villes et communes, aux œuvres littéraires et artistiques, aux noms de personne, ce qui permet une consultation ponctuelle. Les quarante-huit planches en couleur reproduisant les miniatures étudiées dans les différentes contributions enrichissent encore cet ouvrage collectif. 